\title{
Preparing Students For Class: A Clinical Trial Testing The Efficacy Between Multimedia Pre-lectures And Textbooks in an Economics Course
}

\author{
Jose J. Vazquez, Ph.D., University of Illinois, USA
}

Eric P. Chiang, Ph.D., Florida Atlantic University, USA

\begin{abstract}
Motivating students to come prepared to class is often a futile exercise. The consequences are magnified as more instructors adopt the flipped classroom teaching model, in which students are expected to come to class with some knowledge of the material. This paper analyzed the implementation of a pedagogical tool that addresses this problem: multimedia pre-lectures. We tested the efficacy of pre-lectures on students with no prior exposure to college or AP-level economics using a controlled clinical experiment, focusing on introductory economics concepts. Students who had access to pre-lecture materials scored significantly higher on comprehension and retention than those with access only to textbooks.
\end{abstract}

Keywords: Multimedia Pre-Lectures; Flipped Classroom; Instructional Visuals; Economics

\section{INTRODUCTION}

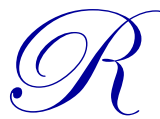

ecent trends in higher education have focused on new pedagogical techniques to increase student motivation and comprehension. This is important because the way in which students learn has changed as a result of new technology in media and communications. Students today tend to be more visual learners that acquire information through short bursts of content, such as those on social media sites. Moreover, the growth of online resources and technologies that complement, and in many situations, substitute, for the traditional "chalk-and-talk" lectures has made pedagogy an important issue. Instructors today have access to a multitude of teaching tools as they are increasingly being offered by publishers as part of their suite of learning resources.

One trend in higher education is the flipped classroom, in which students are asked to review classroom material prior to class, allowing more class time to be used for active learning activities such as group discussion, problem solving, and experiments. The flipped classroom model takes much of the traditional lecture outside of the classroom (becoming the "homework"), while activities previously completed outside of class, such as problem solving and peer-to-peer learning, are moved into the classroom. To facilitate the learning of essential course concepts prior to class, instructors typically assign some form of pre-class assignment using various learning tools. This can be as simple as a set of textbook readings, or it can be a multimedia tool such as PowerPoint slides or videos to serve as the pre-lecture.

This paper examined whether multimedia pre-lectures are more effective than traditional textbooks in preparing students for an economics principles class based on three objectives: (a) motivating students to study course material before class, (b) conveying key concepts in a way that students can comprehend when seen for the first time, and (c) increasing long-term retention of the concepts. We used a controlled clinical trial to evaluate the effectiveness of text-based readings and multimedia pre-lectures.

In the clinical trials, students with no prior exposure to college or AP-level economics were randomly assigned into one of two groups: one that was given only readings from a well-known textbook, and another that was given 
multimedia pre-lectures covering the same topics. Students in both groups were then given the same assessment immediately after the session as well as 2 weeks later to evaluate longer-term retention. Based on the clinical trials, we found evidence that supports the conclusion that multimedia pre-lectures enhanced both the comprehension and retention of economics concepts. Students who watched multimedia pre-lectures scored almost 6 points higher in the immediate assessment than those who had access only to a textbook, and almost 8 points higher in an assessment given 2 weeks later.

In the remainder of this article, the case for multimedia presentations is presented by a summary of research on the effectiveness of visuals in learning outcomes. The clinical trial study and the methodology used is then described, followed by a discussion of the results and their implications. Finally, the importance of our findings is summarized along with direction for further research.

\section{THE CASE FOR VISUAL PRESENTATIONS}

The debate regarding the effectiveness of text versus video is one that stirs strong feelings in the academic community. Purists believe that online technologies and multimedia tools pose a distraction to learning, with the argument that the best form of teaching requires only a well-prepared instructor and a chalkboard, complemented by a textbook. But a growing number of instructors have adapted to technology, complementing their classes with a variety of tools. They argue that today's college students are part of a new generation that grew up with mobile devices and the Internet, and therefore are more accustomed to learning using these tools.

The case for using visual presentations in lieu of text-based presentations in the teaching of economics focuses on two general areas of research: (a) research in neuroscience and cognitive science that studies how the brain functions when stimulated by information presented in various forms, and (b) studies of how existing forms of visual presentations within the economics discipline affect the learning outcomes of students. For the latter, we focused our analysis on economics principles, with an emphasis on assessment outcomes and content retention.

\section{Neuroscience and Cognitive Science}

Although any presentation, including written words or bullet points on a slide, is inherently visual because one must use eyes to see it, for purposes of our research we defined visuals as the use of photos, diagrams, animations, and videos instead of words to deliver an educational message. The rationale for visual presentations derives from decades of research in both neuroscience and cognitive science with respect to two areas of brain function: vision and memory. An in-depth discussion of this research is found in Vazquez and Chiang (2014), which we briefly summarize in the following paragraphs.

The first biological argument for visual presentations is that we see in pictures. One reason why text is less capable than pictures to deliver any message is because the brain sees words as lots of tiny pictures. Data show that a word is unreadable unless the brain can separately identify simple features in the letters (Pelli, Farell, \& Moore, 2003). Hence, reading creates a bottleneck. To our cortex, there is no such thing as words. In fact, when people read, they tend to create mental images of what the text is conveying.

Therefore, the more visual the input becomes, the more likely it is to be recognized and recalled, an effect referred to as the pictorial superiority effect (Endestad, Magnussen, \& Helstrup, 2003; McBride \& Dosher, 2002; Stenberg, 2006). Specifically, the process of vision takes place not in the eye, but in the brain which reconstructs information received from the eyes with previous knowledge stored in memory (Carlson, 2007; Medina, 2008; Fried, Munch, \& Werblin, 2005; Roska, Molnar, \& Werblin, 2006). These studies help to justify why the use of visuals enhances the way knowledge is conveyed in the classroom.

The other argument for visual presentations, the dual coding theory, comes from cognitive science, and suggests that people receive and process information through two distinct but interrelated channels: a verbal channel, which processes verbal material, and a visual channel, which processes pictorial material and nonverbal sounds (Paivio, 1986; Paivio, 2006). 
Figure 1. Memory and the cognitive case for adding pictures to educational lectures

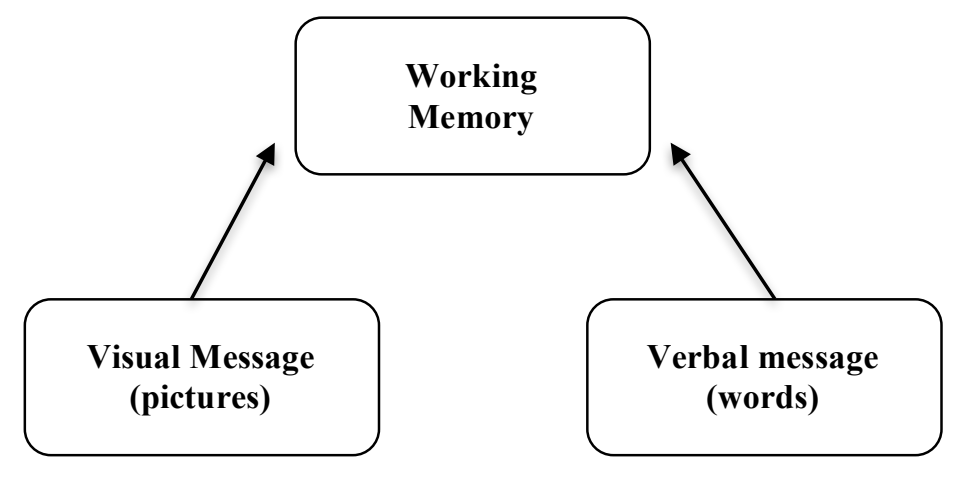

Dual-coding theory leads to two implications for classroom instruction: first, adding an image to any verbal message can enhance the retention of that message in one's memory, and second, a message that is solely text-based has the potential to overwhelm the verbal channel, making retention more difficult. Moreover, when one merely narrates written words, thereby emphasizing words though both the auditory and visual sensors, the ability to process the message may be inhibited due to the verbal channel being overloaded.

\section{Effect of Visuals on Learning Outcomes}

Much of the recent literature on the role of technology in the classroom has focused on the effect that online courses have in supplanting face-to-face courses at universities throughout the United States. Because online courses are natural laboratories for testing the effectiveness of technologies such as learning management systems, lecture capture, video clips, and multimedia slides, much of the existing literature has focused on how the movement toward online courses has affected learning outcomes in economics courses. Because a flipped classroom relies on moving the traditional lecture online into a pre-lecture format, it is useful to briefly examine the effectiveness of online delivery of courses in general.

Recent studies have suggested that although online courses may not be a perfect substitute for a face-to-face classroom, the differences in student outcomes are not significant, and tend to impact certain subgroups of students more than others. For example, Figlio, Rush, and Yin (2013) found that the performance in face-to-face economics courses is marginally higher for Hispanic students, male students, and lower-performing students. Subsequent studies in economics and statistics by Joyce, Crockett, Jaeger, Altindag, and O'Connell (2014) and by Bowen, Chingos, Lack, and Nygren (2014), respectively, showed that courses that met in person more often performed only slightly better than hybrid courses. Bosshardt and Chiang (2016) focused on selection issues in online economics courses. When students have a choice between online and face-to-face formats, that choice is influenced mostly by personal attitudes toward technology and previous experience with online courses. They conclude that if chalk-andtalk can be replicated online, then the advantage of a live classroom lies in the ability to engage in active learning.

A recent compendium of 80 topics on economics education, edited by Hoyt and McGoldrick (2012), contains contributions from dozens of instructors and researchers aimed at improving learning outcomes and concept retention. Although active learning and flipped classrooms were among the more prominent topics discussed, much of the existing research on the effectiveness of a flipped classroom framework has involved other disciplines, most notably physics, which was arguably the pioneer of the flipped classroom (Stelzer, Gladding, Mestre, \& Brookes, 2009). Today, there are an increasing number of papers and books discussing best practices on flipping a classroom in many disciplines (e.g., Bergmann \& Sams, 2012; Roach, 2014; Vazquez \& Chiang, 2015).

The primary challenge of implementing a flipped classroom is determining the best method of conveying essential concepts to students before the class meeting. Historically, this has been encouraged by way of reading the corresponding textbook chapters prior to class. Although instructors have long encouraged students to engage in such proactive learning, empirical and anecdotal evidence suggest that most students do not read textbooks prior to class. For example, in an informal poll of the author's large principles of economics classes in the Fall of $2013,71 \%$ 
of respondents indicated that they "never" or "rarely" read the assigned textbook readings prior to class, despite the fact that extra credit clicker questions were posed during class as an incentive to students to read the textbook. The solution that has become increasingly popular is the development of mini-lectures that consist of either narrated animations or live videos. These short lectures are typically 10 to 15 minutes in length, visually-intensive, and often are embedded with questions to assess student understanding and retention. The result has been the creation of two types of mini-lectures: (a) pre-lectures, which assume that students have no prior knowledge of the topic and are aimed at students prior to class; and (b) summary lectures, which serve as a review tool for students to watch after a class. Pre-lectures tend to be used more frequently in a flipped classroom setting, and is the format we studied in this research.

Studies of the effectiveness of pre-lecture videos on learning outcomes using controlled clinical trials have rarely been conducted. Instead, most studies analyze outcomes using an instructor's own classes. However, that approach is subjected to the biases stemming from external factors influencing a student's performance in a class that a clinical trial in a controlled lab setting can avoid. Prior clinical trials focusing on the effectiveness of videos include those by Stelzer et al. (2009), who found a profound positive effect on learning outcomes in physics, and Lusardi, Samek, Kapteyn, Glinert, Hung, and Heinberg (2014), who concluded that videos were much more effective than written narratives in conveying financial literacy. Both studies were conducted in a lab setting, and both showed that the use of visual tools and video is more engaging and results in greater confidence in knowledge which translates to improved learning.

This article focuses on two learning outcomes: (a) the extent to which students without any prior knowledge of a topic is able to recall and understand economics concepts, and (b) the extent to which students are able to retain information over a longer term. Both learning outcomes are critical for assessing the level of preparedness by students prior to class. These results carry important implications for the future of teaching pedagogy such as the flipped classroom and the resources that are being developed to prepare students for class.

\section{EMPIRICAL STUDY DESCRIPTION}

In order to test the benefits of multimedia pre-lectures, we focused on four major topics in a principles of microeconomics: production possibilities frontier (PPF), the benefits of trade (Trade), price elasticity of demand (PED), and other elasticities (OE). These are typically among the most challenging topics in an economics principles course, and therefore are ideal to investigate which type of presentation mode works best to help students learn and retain economics concepts.

\section{Multimedia Pre-Lectures}

We developed four multimedia learning modules (pre-lectures), one for each of the four topics addressed in this research. Each pre-lecture covered one lecture's worth of course content and was divided into approximately eight scenes. Each scene was implemented as a video containing dynamic animations synchronized with an audio narration that was controlled by the student (pause, play, and rewind). We also included embedded formative questions in two or three scenes in each pre-lecture. These questions must be answered correctly before the student can proceed to the next scene. Note that the pre-lectures were not designed to replicate an entire lecture, but instead to provide a visual introduction to the key concepts. The average narration time of a pre-lecture is 12 minutes, but students took an average of 17 minutes to complete a single pre-lecture including the embedded questions.

The second presentation mode consisted of a brief set of pdf pages from a leading principles textbook: Mankiw's Principles of Microeconomics $6^{\text {th }}$ edition (2011). We used a few pages of text from each topic along with the worked examples and practice problems. The use of these pages for research purposes falls within fair use guidelines; the total number of pages used constituted less than $4 \%$ of the book. The length of the readings was limited to an amount that could adequately be read and studied within the allotted time limit. 


\section{Study Procedures}

We recruited volunteers during the Fall 2013 semester by offering an incentive of a $\$ 50$ Amazon gift card for participating in the study. All participants had never previously taken a college or AP-level economics course. All students came to a computer lab for three different sessions: two base sessions and a retention session. Each base session consisted of two parts: presentation and assessment, each lasting about 30 minutes. In the presentation phase, students were randomly assigned into one of two groups: study and control.

- Study group (Video): Students in this group were shown the multimedia pre-lecture videos.

- Control group (Text): Students in this group were shown the textbook chapters.

Table 1 shows descriptive statistics for relevant study variables between the control group and study group. As the statistics show, there are no significant differences between the two groups for any variables, which suggests that the process of randomization of students into the samples was successful.

Table 1. Descriptive Statistics for Relevant Study Variables

\begin{tabular}{|c|c|c|c|c|c|c|c|c|c|c|}
\hline & \multirow{2}{*}{\multicolumn{2}{|c|}{$\frac{\mathbf{N}}{\text { Group }}$}} & \multirow{2}{*}{\multicolumn{2}{|c|}{$\begin{array}{l}\text { Minimum } \\
\text { Group }\end{array}$}} & \multirow{2}{*}{\multicolumn{2}{|c|}{$\begin{array}{l}\text { Maximum } \\
\text { Group } \\
\end{array}$}} & \multirow{2}{*}{\multicolumn{2}{|c|}{$\begin{array}{l}\text { Mean } \\
\text { Group }\end{array}$}} & \multirow{2}{*}{\multicolumn{2}{|c|}{$\frac{\text { Std. Deviation }}{\text { Group }}$}} \\
\hline & & & & & & & & & & \\
\hline & Text & Video & Text & Video & Text & Video & Text & Video & Text & Video \\
\hline Male & 41.0 & 41.0 & 0.0 & 0.0 & 1.0 & 1.0 & 0.6 & 0.5 & 0.5 & 0.5 \\
\hline Age & 41.0 & 41.0 & 19.0 & 19.0 & 30.0 & 26.0 & 21.2 & 20.7 & 2.3 & 1.5 \\
\hline ACT Composite & 37.0 & 39.0 & 21.0 & 20.0 & 35.0 & 35.0 & 29.4 & 29.3 & 4.1 & 3.9 \\
\hline Cumulative GPA & 41.0 & 41.0 & 1.5 & 0.7 & 4.0 & 4.0 & 3.2 & 3.2 & 0.6 & 0.8 \\
\hline Math Course Credit Earned & 41.0 & 41.0 & 0.0 & 0.0 & 19.0 & 18.0 & 4.8 & 5.4 & 6.0 & 5.4 \\
\hline
\end{tabular}

The assessment phase consisted of a quiz with 24 multiple choice questions relating to the material covered in the presentation phase. All students returned to the lab for a retention session 2 weeks after the last base session to complete a quiz consisting of 20 multiple choice questions. This session lasted 30 minutes.

Figure 2. Experimental design at a glance.

\begin{tabular}{|c|c|c|}
\hline Base Session 1 (Monday) & Base Session 2 (Wednesday) & Retention Session (2 weeks later) \\
\hline $\begin{array}{l}\text { - PPF and Trade topics } \\
\text { - Presentation ( } 30 \text { minutes): Students } \\
\text { watch pre-lecture videos or read booklet } \\
\text { - Assessment ( } 30 \text { minutes): } 24 \text { multiple } \\
\text { choice questions }\end{array}$ & $\begin{array}{l}\text { - PED and OE topics } \\
\text { - Presentation ( } 30 \text { minutes): Students } \\
\text { watch pre-lecture videos or read booklet } \\
\text { - Assessment ( } 30 \text { minutes): } 24 \text { multiple } \\
\text { choice questions }\end{array}$ & $\begin{array}{l}\text { - Assessment ( } 30 \text { minutes): } \\
\text { Students take an assessment } \\
\text { exam consisting of } 20 \text { multiple } \\
\text { choice questions. }\end{array}$ \\
\hline
\end{tabular}

\section{METHODOLOGY}

Our first hypothesis was that students in the study (video) group would achieve a higher assessment score than those in the control (textbook) group. To test this hypothesis, we used the following regression equation:

Model 1: Post-Assessment Score $=\beta_{0}+\beta_{1}$ video $_{i}+\beta_{2} A C T_{i}+\beta_{3} X_{i}+\varepsilon_{i}$

where Post-Assessment Score is the score the student obtained in an assessment (consisting of 48 multiple choice questions) taken immediately after the study session (watching the videos or reading the text); video is a dummy variable equal to 1 if the student was in the study (video) group, $A C T$ is the score that the students achieved on the standardized ACT exam as reported from their transcripts, and $X$ is a set of demographic variables, including age and gender. The parameter of interest is ${ }^{-1}$, which represents the change in the average score resulting from watching the pre-lectures in lieu of reading the text. 
Our second hypothesis is that presenting the material in video format will also improve a student's retention of the concepts. To test this hypothesis, we used the following regression equation:

Model 2: Retention Score $=\beta_{0}+\beta_{1}$ video $_{i}+\beta_{2} A C T_{i}+\beta_{3} X_{i}+\varepsilon_{i}$

where Retention Score is the score the student achieved from an assessment consisting of 20 multiple choice questions taken 2 weeks after the initial assessment taken immediately after the study session. Students from both groups took the same assessment quiz for the purposes of evaluating the extent of subject matter retention.

\section{EMPIRICAL RESULTS}

Table 2 shows the ordinary least squares (OLS) regression results from Model 1. Holding all other variables constant, students in the study (video) group on average scored almost 6 points higher on the assessment quiz than students in the control (textbook) group. These results are statistically significant at the 0.05 level. Therefore, our hypothesis that students are able to learn and understand the material better by watching videos, instead of reading text, is supported by our results.

Table 2. Results from OLS Regression on Model $1(\mathrm{n}=82)$

\begin{tabular}{l|cc}
\hline \multirow{2}{*}{ Model } & \multicolumn{2}{c}{ Unstandardized Coefficients } \\
\cline { 2 - 3 } & B & Std. Error \\
\hline Group & $5.825^{*}$ & 2.768 \\
\hline Gender & 4.891 & 2.996 \\
\hline Age & $2.559^{*}$ & 1.201 \\
\hline Math Course Credit Earned & 0.463 & 0.273 \\
\hline ACT Composite & $2.201^{* *}$ & 0.392 \\
\hline
\end{tabular}

Notes: $* * p<0.01, * p<0.05$

Table 3 shows the OLS regression results from Model 2, estimating the retention of concepts 2 weeks later. Holding all other variables constant, the study (video) group scored almost 8 points higher in the retention assessment quiz than a student in the control (textbook) group. These statistically significant results suggest that the effect of multimedia videos had an even greater benefit on concept retention.

Table 3. Results from OLS Regression on Model $2(\mathrm{n}=82)$

\begin{tabular}{l|c|c}
\hline \multirow{2}{*}{ Model } & \multicolumn{2}{c}{ Unstandardized Coefficients } \\
\cline { 2 - 3 } & B & Std. Error \\
\hline Group & $7.758^{*}$ & 3.340 \\
\hline Gender & 4.255 & 3.614 \\
\hline Age & 1.863 & 1.449 \\
\hline Math Course Credit Earned & 0.533 & 0.329 \\
\hline ACT Composite & $1.921^{* *}$ & 0.473 \\
\hline
\end{tabular}

Notes: $* * p<0.01, * p<0.05$

Both assessment test scores, base and retention, included all questions from the assessments. However, some questions are different in terms of the skills required to answer them. To evaluate whether the marginal benefit of multimedia presentations is different depending on the type of question asked, we classified all questions according to Anderson and Krathwohl's updated version of Bloom's taxonomy of cognition domain (Anderson \& Krathwohl, 2001). Level-1 includes questions requiring remembering, Level-2 includes questions requiring understanding, Level-3 includes questions requiring applying, and Level-4 includes questions requiring analyzing. We ran the model again for each of the four categories. Table 4 shows the results of the OLS regression coefficients for these regressions. 
Table 4. OLS Estimates By Cognitive Domain Level $(\mathrm{n}=82)$

\begin{tabular}{|c|c|c|c|c|}
\hline & Level-1 & Level-2 & Level-3 & Level-4 \\
\hline Group & $\begin{array}{c}5.73 \\
(3.81)\end{array}$ & $\begin{array}{c}9.06^{* *} \\
(3.60)\end{array}$ & $\begin{array}{c}1.60 \\
(3.53)\end{array}$ & $\begin{array}{l}16.58^{*} \\
(7.71)\end{array}$ \\
\hline Gender & $\begin{array}{c}3.97 \\
(4.13)\end{array}$ & $\begin{array}{c}7.72^{*} \\
(3.90)\end{array}$ & $\begin{array}{c}0.70 \\
(3.87)\end{array}$ & $\begin{array}{c}8.10 \\
(8.49)\end{array}$ \\
\hline Age & $\begin{array}{c}3.94 * \\
(1.66)\end{array}$ & $\begin{array}{c}1.60 \\
(1.57)\end{array}$ & $\begin{array}{c}2.85^{*} \\
(1.54)\end{array}$ & $\begin{array}{l}-0.42 \\
(3.38)\end{array}$ \\
\hline Math Course Credit Earned & $\begin{array}{c}0.41 \\
(0.38)\end{array}$ & $\begin{array}{c}0.28 \\
(0.37)\end{array}$ & $\begin{array}{c}0.46 \\
(0.37)\end{array}$ & $\begin{array}{c}1.70^{*} \\
(0.76)\end{array}$ \\
\hline ACT Composite & $\begin{array}{l}2.30^{* * * *} \\
(0.54)\end{array}$ & $\begin{array}{l}1.72^{* * *} \\
(0.51)\end{array}$ & $\begin{array}{l}2.64^{* * *} \\
(0.50)\end{array}$ & $\begin{array}{c}2.10^{* *} \\
(1.11)\end{array}$ \\
\hline Adjusted R-squared & 0.28 & 0.26 & 0.34 & 0.20 \\
\hline
\end{tabular}

The results suggest that the marginal benefit from multimedia lectures was highest, and most statistically significant, for levels 2 and 4; understanding and analyzing, respectively. In fact, students in the video group scored 16 points higher on questions in level 4 . These results suggest that the benefits of multimedia pre-lectures depend on the type of question, particularly its cognitive level.

To further contrast the effectiveness of multimedia pre-lectures and textbook readings, we asked each participant to convey their opinions on their experience with the learning process. Specifically, we asked how confident they felt with their understanding of the material after finishing the module. The results are shown in Figure 3 . Of the students in the Video group, $44 \%$ felt they understood the concept either well or very well. This is in comparison to just $36 \%$ in the Text group. Therefore, the results suggest that students in the Video group not only scored better, but also self-reported better understanding of the material.

Figure 3. Responses to "After completing this module, how well did you understand the concept being presented?"

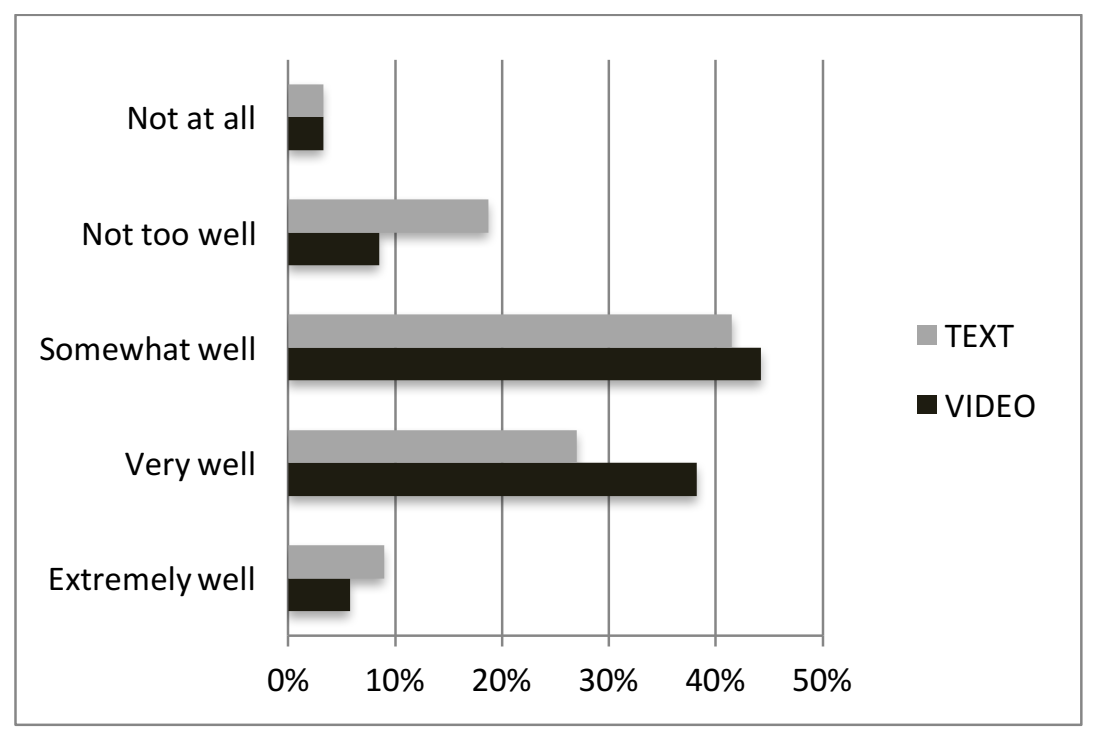

Our findings from the clinical trials point to several important takeaways. First, from a cognitive and neurological perspective, individuals comprehend and retain more information when absorbed using both the visual and verbal channels. In our case, a visual and audio presentation performed better than a text-based presentation. Second, from a practical perspective, nearly all students today grew up with Internet and mobile technologies, and therefore are generally more comfortable learning using these tools. Our findings suggest that the marginal effect of students' comfort level with technology may contribute to their enhanced understanding and retention of concepts when presented in this format. 


\section{CONCLUSION}

This article makes a strong argument for the use of multimedia modules in the form of pre-lectures to complement the way in which economics concepts are conveyed to students. Multimedia pre-lectures have been found not only to promote retention of information, but also to aid significantly in the understanding of concepts seen for the first time by allowing the brain to make visual connections between images and concepts.

To study the effectiveness of visuals empirically, we used a clinical trial to compare the understanding and retention of economics concepts by students placed in a study group that received multimedia pre-lectures of the concepts, and a control group that received only written text of the concepts. Students in the study (video) group scored almost 6 points higher on average on the initial assessment. This difference in scores increased to almost 8 points in a second assessment that both groups took 2 weeks after the initial assessment. Therefore, our findings provide strong evidence that students can learn and retain concepts more effectively when conveyed using a medium that incorporates a greater visual presentation as opposed to just words alone. These findings support those found by researchers in other disciplines such as in physics (Stelzer et al., 2009).

The importance of these findings is highlighted by the fact that more instructors are choosing to flip their classrooms. Some instructors create time for active learning by simply replacing traditional lectures (i.e., chalk-andtalk) from the student's learning path with assigned textbook readings before class. Our findings suggest this strategy may be counterproductive, because it denies the student an effective way of receiving basic information for the first time: the spoken lecture. Instead, we suggest that instructors move the traditional lecture outside the classroom by assigning students pre-recorded multimedia lectures that better replicate the chalk-and-talk experience, thereby preparing students for a more effective active learning experience in the classroom.

There are certainly additional avenues of future research. For example, although our results suggest that comprehension and retention may improve even further if students are given both mediums (videos and text), clinical trials of this effect have not yet been tested. In addition, additional study on whether learning styles affect outcomes may be useful, as one could argue that some students are more visual learners while others are not. Moreover, it would be useful to determine whether our results apply to advanced courses that are more technical.

It is important to caution readers, however, that our results do not suggest that instructors should stop using textbooks in their courses. A textbook serves many purposes beyond simply introducing students to the material for the first time. A textbook serves a critical function as a reference for more in-depth discussion and analysis of the concepts, as well as a mechanism to convey and discuss important real-world applications.

Our results do suggest that textbooks are not as efficient as multimedia videos at introducing concepts to novices for the first time. This conclusion has particular relevance to any instructors trying to flip their classroom, because it suggests that replacing the typical chalk-and-talk lecture by assigning readings from the textbook results in a less efficient tradeoff for the student. A more effective way of flipping the classroom, at least for introductory courses, is to offer the chalk-and-talk lecture to students in the form of a multimedia presentation.

As new resources become increasingly available to prepare students for class, opportunities to improve the learning experience by students and the teaching experience by instructors will increase. This is especially the case as more instructors adopt active learning exercises in their classes, which encourages students to become teachers, and teachers to become facilitators. As online courses increasingly replace chalk-and-talk classes, the flipped classroom may be the face-to-face teaching method that ultimately survives.

\section{AUTHOR BIOGRAPHIES}

Jose J. Vazquez, Ph.D., is a Clinical Professor at the University of Illinois Urbana-Champaign, where he teaches one of the largest face-to-face economics courses in the United States (900+ students). He is also the Coordinator of e-Learning, as well as the Director of the Teaching Academy for the School of Liberal Arts and Sciences. During his tenure at Illinois he has received several teaching awards, including Outstanding Teacher of Freshmen Award. He is also the co-creator of FlipIt Economics, a multimedia solution that helps students prepare effectively for class. Email: vazquezj@illinois.edu 
Eric P. Chiang, Ph.D., is an Associate Professor of Economics and Director of Instructional Technology at Florida Atlantic University. He oversees all online lecture capture courses in the College of Business with an enrollment exceeding 5,200 per term, as well as coordinates the Online MBA program. He has won numerous teaching awards including the FAU Distinguished Teacher of the Year. He is the author of CoreEconomics, a principles of economics textbook, and co-creator of FlipIt Economics. Email: chiang@fau.edu

\section{REFERENCES}

Anderson, L.W. (Ed.), Krathwohl, D.R. (Ed.), Airasian, P.W., Cruikshank, K.A., Mayer, R.E., Pintrich, P.R., Raths, J., \& Wittrock, M.C. (2001). A taxonomy for learning, teaching, and assessing: A revision of Bloom's taxonomy of educational objectives. New York, NY: Longman.

Bergmann, J., \& Sams, A. (2012). Flip your classroom: Reach every student in every class every day. Eugene, OR: International Society for Technology in Education.

Bosshardt, W., \& Chiang, E. P. (2016). Lecture capture learning: Do students perform better compared to face-to-face classes? Southern Economic Journal. 82(3),1021-1038.

Bowen, W. G., Chingos, M. M., Lack, K. A., \& Nygren, T. I. (2014). Interactive learning online at public universities: Evidence from a six-campus randomized trial. Journal of Policy Analysis and Management, 33(1), 94-111.

Carlson, N. R. (2007). Physiology of behavior (Ninth Edition). New York, NY: Pearson.

Endestad, T., Magnussen, S., \& Helstrup T. (2003). Memory for pictures and words following literal and metaphorical decisions. Imagination, Cognition and Personality, 23(2-3), 209-216.

Figlio, D., Rush, M., \& Yin, L. (2013). Is it live or is it Internet? Experimental estimates of the effects of online instruction on student learning. Journal of Labor Economics, 31(4), 763-784.

Fried, S. I., Munch, T. A., \& Werblin, F. S. (2005). Directional selectivity is formed at multiple levels by laterally offset inhibition in the rabbit retina. Neuron, 46, 117-127.

Hoyt, G. M., \& McGoldrick, K. (2012). International handbook on teaching and learning economics. Northampton, MA: Edward Elgar.

Joyce, T. J., Crockett, S., Jaeger, D. A., Altindag, O., \& O’Connell, S.D. (2014). Does classroom time matter? A randomized field experiment of hybrid and traditional lecture formats in economics. NBER Working Paper No. 20006.

Lusardi, A., Samek, A., Kapteyn A., Glinert, L, Hung A, \& Heinberg, A. (2014). Visual tools and narratives: New ways to improve financial literacy. NBER Working Paper No. 20229.

Mankiw, N. G. (2011). Principles of microeconomics. Boston, MA: Cengage Learning.

McBride, D. M., \& Dosher, B. A. (2002). A comparison of conscious and automatic memory processes for picture and word stimuli: A process dissociation analysis. Consciousness and Cognition, 11(3), 423-460.

Medina, J. J. (2008). Brain Rules. Seattle, WA: Pear Press.

Paivio, A. (1986). Mental Representations: A dual coding approach. Oxford, England: Oxford University Press.

Paivio A. (2006). Mind and Its Evolution: A dual coding theoretical approach. New York, NY: Psychology Press.

Pelli, D. G., Farell, B., \& Moore, D. C. (2003). The remarkable inefficiency of word recognition. Nature, 423, $752-756$.

Roach, T. (2014). Student perceptions toward flipped learning: New methods to increase interaction and active learning in economics. International Review of Economics Education, 17, 74-84.

Roska, B., Molnar, A., \& Werblin, F. S. (2006). Parallel processing in retinal ganglion cells: How integration of space-time patterns of excitation and inhibition form the spiking output. Journal of Neurophysiology, 95, 3810-3822.

Stelzer, T., Gladding, G., Mestre, J. P., \& Brookes, D. T. (2009). Comparing the efficacy of multimedia modules with traditional textbooks for learning introductory physics content. American Journal of Physics, 77(2), 184-190.

Stenberg, G. (2006). Conceptual and perceptual factors in the picture superiority effect. European Journal of Cognitive Psychology, 18(6), 813-847.

Vazquez, J., \& Chiang, E. P. (2014). A picture is worth a thousand words (at least): The effective use of visuals in the economics classroom. International Review of Economics Education, 17, 109-119.

Vazquez, J., \& Chiang, E. P. (2015). Flipping out! A case study on how to flip the principles of economics classroom. International Advances in Economic Research, 21, 379-390. 
NOTES 